
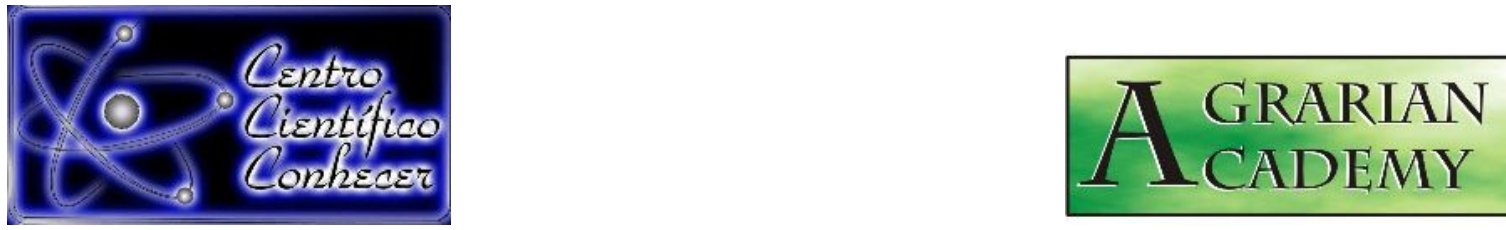

\title{
ÁREA DE CLADÓDIO DA PALMA Opuntia Stricta UTILIZANDO DIMENSÕES LINEARES
}

Leandro Ricardo Rodrigues de Lucena'; Maurício Luiz de Mello Vieira Leite'; Vicente José Laamon Pinto Simões² ; Vicente José Laamon Pinto Simões²; Mirna Clarissa Rodrigues de Almeida ${ }^{3}$

1Prof. Dr. Departamento de Zootecnia, Universidade Federal Rural de Pernambuco, Serra Talhada, PE, Brasil, Serra Talhada, PE, Brasil

(leandroricardo_est@yahoo.com.br);

${ }^{2}$ Prof. Dr. Departamento de Agronomia, Universidade Federal Rural de Pernambuco, Serra Talhada, PE, Brasil;

3 Discente de Pós-Graduação em Produção Vegetal, Universidade Federal Rural de Pernambuco, Serra Talhada, PE, Brasil,

Recebido em: 14/07/2018 - Aprovado em: 28/07/2018 - Publicado em: 31/07/2018 DOI: 10.18677/Agrarian_Academy_2018a5

A palma forrageira Orelha de Elefante Mexicana possui elevada adaptação ao clima quente, tolerância à seca, e apresenta boa aceitação pelos animais. Objetivou definir o melhor modelo para estimativa da área de cladódio do clone Orelha de Elefante Mexicana, de forma não destrutiva, com base nas dimensões lineares do comprimento e da largura do cladódio e área da elipse. Os modelos foram avaliados pelo coeficiente de determinação do modelo, soma de quadrados dos resíduos e critério de informação de Akaike. Os resultados mostraram que o modelo linear levando em consideração as variáveis explicativas: produtos do comprimento pela largura do cladódio e área da elipse se ajustaram bem aos valores da área real do cladódio. Os modelos de regressão lineares apresentaram grau de explicação de $96,66 \%$ e $96,77 \%$, respectivamente. O modelo de regressão linear utilizando a área da elipse como variável explicativa foi escolhido para explicar a área real do cladódio de palma Orelha de Elefante Mexicana, pois apresentou os melhores critérios de adequação dos modelos.

PALAVRAS-CHAVE: Dimensões lineares; Modelagem; Modelo Linear.

\section{CLADODE AREA OF PALM Opuntia Stricta USING LINEAR DIMENSIONS}

\footnotetext{
ABSTRACT

The forage palm of Mexican Elephant Ear is highly adapted to the hot climate, drought tolerant, and has good accepted by animals. Aimed to define the best model for estimating the cladode area of Mexican Elephant Ear clone, in a non- destructive manner, based on the linear dimensions of cladode length and width and ellipse AGRARIAN ACADEMY, Centro Científico Conhecer - Goiânia, v.5, n.9; p.46 2018
} 
area. The models were evaluated by coefficient of determination of model, sum of squares of residues and criteria of information of Akaike. The results showed that linear models taking into account the explanatory variables: products of the length by width of cladode and area of ellipse fit well to the values of the real area of cladode. Linear regression models presented explanations of $96.66 \%$ and $96.77 \%$, respectively. The linear regression model using the ellipse area as an explanatory variable was chosen to explain the real area of cladode of Mexican Elephant Ear, as it presented the best criteria for the adequacy of models.

KEYWORDS: Linear dimensions; Modeling; Linear model.

\section{INTRODUÇÃO}

A palma forrageira (Opuntia sp. e Nopalea sp.) possui elevada adaptação ao clima quente, tolerância à seca (SILVA et al., 2014), boa produção de massa seca (RAMOS et al., 2011), altos teores de carboidratos não fibrosos (DUBEUX JR et al., 2010) e nutrientes digestíveis totais (ANDRADE et al., 2016), destacando-se como uma alternativa forrageira para a sustentabilidade da pecuária, principalmente, nas regiões semiáridas. No entanto, o rendimento da cultura é influenciado por diversos fatores, entre eles, está à interceptação luminosa, que por sua vez, é determinada pelas características morfológicas como, por exemplo, o índice de área do cladódio e comprimento do cladódio (PINHEIRO et al., 2014).

A palma forrageira apresenta uma estrutura diferente das demais forrageiras, como gramíneas e leguminosas, onde o aparelho fotossintético é localizado nas folhas. $\mathrm{Na}$ palma, está localizado no cladódio, o qual é responsável pela interceptação e uso da radiação solar no processo fotossintético, promovendo a produção de carboidratos e de biomassa seca, denominando-se nessa cultura, área foliar de área de cladódio. A eficiência fotossintética e o rendimento da palma forrageira apresentam variações em razão do clone utilizado, uma vez que, há uma diferenciação na emissão, distribuição, formato e tamanho dos cladódios entre os clones (SILVA et al., 2010).

A determinação da área foliar é uma ferramenta importante para estudar a intensidade de transpiração, razão de área foliar, área foliar específica e índice de área foliar (SCHMILDT et al., 2014). A palma forrageira apresenta uma estrutura diferente das demais forrageiras, como gramíneas e leguminosas, onde o aparelho fotossintético é localizado nas folhas. Na palma, está localizado no cladódio, denominando-se na palma forrageira, área foliar de área de cladódio.

Para a estimativa de área foliar, atualmente, são utilizados vários métodos. Os métodos são classificados em destrutivos ou não destrutivos e diretos ou indiretos (LEITE et al., 2017). Os métodos não destrutivos e indiretos são baseados em relações entre a variável biométrica mensurável e a área foliar real (SBRISSIA; SILVA, 2008; FLUMIGNAN et al., 2008) e permitem avaliações sucessivas em uma mesma planta e rapidez nas avaliações (TOEBE et al., 2012).

O desenvolvimento de modelos de regressão utilizando medidas lineares de folhas para explicar a área foliar tem se mostrado muito útil no estudo do crescimento e desenvolvimento de plantas (ACHTEN et al., 2010). Os modelos matemáticos apresentam vantagens por serem relativamente rápidos, não exigir a destruição das plantas e ser de fácil utilização em condições de campo (LEITE et al., 2017).

Vários estudos sobre relações da área foliar e as dimensões foliares tem sido estabelecida para diversas culturas: café (ANTUNES et al., 2008), Crotalaria juncea 
L. (CARDOZO et al., 2011), acerola (LUCENA et al., 2011), girassol (AQUINO et al., 2011), maracujá (MORGADO et al., 2013), Pornunça (SILVA et al., 2017), abacaxi (FRANCISCO et al., 2014), Mucuna (CARGNELUTTI FILHO et al., 2012), mangueira (LIMA et al., 2012), e têm gerado equações com excelente precisão de estimativa.

Embora existam informações em relação às características agronômicas do clone Orelha de Elefante Mexicana, não foram detectados na literatura trabalhos com estimativas da área do cladódio deste clone. Deste modo, objetivou-se definir os melhores modelos para estimativa da área de cladódio do clone Orelha-deElefante-Mexicana, de forma não destrutiva, com base nas dimensões lineares do comprimento e da largura do cladódio.

\section{MATERIAL E MÉTODOS}

A pesquisa foi conduzida de 20 de setembro de 2016 a 20 de dezembro de 2017, no setor de Forragicultura da Universidade Federal Rural de Pernambuco (UFRPE), Unidade Acadêmica de Serra Talhada (UAST), localizada sob as coordenadas geográficas $07^{\circ} 57^{\prime} 01^{\prime \prime} \mathrm{S}$ e $38^{\circ} 17^{\prime} 53^{\prime \prime} \mathrm{O}$, com altitude aproximada de 523 m, situada no município de Serra Talhada, Microrregião do Sertão do Pajeú, Mesorregião do Sertão Pernambucano.

O clima local é do tipo BSwh', de acordo com a classificação de Koppen, com chuvas de verão, iniciando-se em novembro com término em abril, sendo o mês de março historicamente o mais chuvoso. A precipitação pluvial média anual é de 632,2 $\mathrm{mm}$, a temperatura do ar média anual de $26^{\circ} \mathrm{C}$ e umidade relativa do ar média de 60\% (LEITE et al., 2017).

O solo utilizado no experimento, classificado como luvissolo crômico, conforme descrito pela Embrapa, (2017), foi coletado na profundidade de $0-20 \mathrm{~cm}$ do perfil, destorroado, homogeneizado, passado em peneira com malha de 2,0 mm, submetido ao revolvimento para secagem ao ar durante 10 dias e acondicionado em vasos plásticos, perfurados no fundo para drenagem da água de irrigação. Amostra desse solo foi analisada pelo laboratório de fertilidade do solo da Empresa Pernambucana de Pesquisa Agropecuária (IPA), caracterizado pelos seguintes atributos químicos: $\mathrm{pH}$ (água) $=7,20 ; \mathrm{P}$ (extrator Mehlich I) $=40 \mathrm{mg} \mathrm{dm}^{-3} ; \mathrm{K}^{+}=0,45$; $\mathrm{Ca}^{2+}=5,3 ; \mathrm{Mg}^{2+}=1,1 ; \mathrm{Na}^{+}=0,06 ; \mathrm{Al}^{3+}=0,0 ; \mathrm{H}^{+}=1,23 ; \mathrm{SB}=6,91 ; \mathrm{CTC}=8,14$ (cmolc $\mathrm{dm}^{-3}$ ) e V $=84,89 \%$.

Para a determinação da área de cladódio, foram coletadas aleatoriamente, um total de 47 cladódios da palma Orelha-de-Elefante-Mexicana, livres de danos e ataques de doenças ou pragas, em distintos estádios de crescimento e, consequentemente, com diferentes tamanhos, conforme metodologias já consagradas na literatura (LUCENA et al., 2011; SCHMILDT et al., 2014; LEITE et al., 2017).

Em seguida, os cladódios foram numerados de 1 a 47 , e mensurados, determinando-se o comprimento $(\mathrm{C}, \mathrm{em} \mathrm{cm})$ e a largura $(\mathrm{L}, \mathrm{em} \mathrm{cm})$ de cada cladódio com fita milimetrada. A região de maior largura e comprimento do cladódio foi utilizada para medição dessas duas características. Com os valores de $C$ e de $L$, determinou-se 0 produto entre $C$ e $L\left(C^{*} L\right.$, em $\left.\mathrm{cm}^{2}\right)$. A área da elipse $\left(3,1415^{*} \mathrm{C} / 2^{*} \mathrm{~L} / 2\right)$ referente a cada cladódio também foi calculada.

Após a determinação do comprimento e da largura, cada cladódio foliar foi cuidadosamente contornado com grafite sobre folhas de papel milimetrado, formando-se assim, desenhos de cladódios com dimensões iguais ao cladódio analisado, conforme metodologia descrita por Leite et al. (2017). Em seguida, esses 
contornos foram cortados com tesoura e pesados em balança analítica. Após esse procedimento, foi recortado um quadrado de papel da mesma procedência dos desenhos anteriores, com dimensão de $10 \mathrm{~cm} \times 10 \mathrm{~cm}$, equivalente a $100 \mathrm{~cm}^{2}$, pesando $0,630 \mathrm{~g}$. Assim, sabendo-se a massa equivalente a $100 \mathrm{~cm}^{2}$ de papel milimetrado, foi possível determinar, de forma proporcional, a área real de cada cladódio analisado.

A partir dessa análise, utilizando-se o método das dimensões lineares com os dados dos 47 cladódios, foi realizado o estudo de correlação e de análise de regressão da área real de cladódio $(A R C)$, considerada como variável dependente $\left(\mathrm{Y}_{\mathrm{i}}\right)$, com o produto do comprimento pela largura $\left(\mathrm{CL}_{\mathrm{i}}\right)$ e da área da elipse do cladódio $\left(A E_{i}\right)$, variável independente, determinando assim, as equações de regressão para estimativa da área de cladódio.

Para a escolha do modelo que pudesse estimar a área do cladódio em função das dimensões lineares, procederam-se estudos de regressão utilizando os modelos: linear com distribuição normal, assumindo que a resposta da variável dependente esteja no intervalo $(-\infty ; \infty)$, linear com distribuição Gamma, assumindo que a resposta da variável dependente esteja no intervalo $(0 ; \infty)$ e o modelo potência (Tabela 1).

TABELA 1. Modelos de regressão para explicar a área real de cladódio do clone Orelha-de-Elefante-Mexicana em relação à variável explicativa, produto do comprimento pela largura $(\mathrm{CL})$ e área da elipse (AE)

\begin{tabular}{lrr}
\hline \multirow{2}{*}{ Modelos } & \multicolumn{2}{c}{ Variáveis Explicativas } \\
\cline { 2 - 3 } Linear & $Y_{i}=\beta_{0}+\beta_{1} C L_{i}+\varepsilon_{i}$ & $Y_{i}=\beta_{0}+\beta_{1} A E_{i}+\varepsilon_{i}$ \\
Gamma & $Y_{i}=\beta_{0}+\beta_{1} C L_{i}+\varepsilon_{i}$ & $Y_{i}=\beta_{0}+\beta_{1} A E_{i}+\varepsilon_{i}$ \\
Potência & $Y_{i}=\beta_{0} C L_{i}{ }^{\beta_{1}} \varepsilon_{i}$ & $Y_{i}=\beta_{0} A E_{i}{ }^{\beta_{1}} \varepsilon_{i}$ \\
\hline
\end{tabular}

Sejam $Y_{i}$ a i-ésima área real de cladódio; $\mathrm{CL}_{\mathrm{i}}$ o produto entre comprimento e a largura do i-ésimo cladódio; $A E_{i}$ a área da elipse do i-ésimo cladódio e $\varepsilon_{i}$ o i-ésimo erro associado a área real de cladódio, em que $\varepsilon_{\mathrm{i}}$ apresenta distribuição normal de média 0 e variância constante $\sigma^{2}>0$ para os modelos linear e potência e distribuição Gamma de parâmetros $\alpha$ e $\beta$ para os modelos Gamma. As incógnitas $\beta_{0}$ e $\beta_{1}$ são os parâmetros associados aos modelos.

Os modelos foram avaliados pelos seguintes critérios: Coeficiente de determinação do modelo $\left(R^{2}\right)$, critério de informação de Akaike (AIC) definido por Akaike (1974) e pela soma de quadrado de resíduo (SQR), Tabela 2.

TABELA 2. Critério de Avaliação dos Modelos

\section{Critérios de adequação do modelo}

\begin{tabular}{cc}
\hline $\mathrm{R}^{2}$ & $1-\frac{\sum_{\mathrm{i}=1}^{\mathrm{n}}\left(\mathrm{Y}_{\mathrm{i}}-\widehat{\mathrm{Y}}_{1}\right)^{2}}{\sum_{i=1}^{\mathrm{n}}\left(\mathrm{Y}_{\mathrm{i}}-\overline{\mathrm{Y}}_{1}\right)^{2}}$ \\
AIC & $-2 \ln \mathrm{L}(\mathrm{x} \backslash \widehat{\theta})+2(\mathrm{p})$ \\
SQR & $\sum_{\mathrm{i}=1}^{\mathrm{n}}\left(\mathrm{Y}_{\mathrm{i}}-\widehat{\mathrm{Y}}_{1}\right)^{2}$ \\
\hline
\end{tabular}


$L(x \mid \hat{\theta})$ é a função de máxima verossimilhança, definida como sendo o produtório da função de densidade e $\mathrm{p}$ é a quantidade de parâmetros do modelo; $\widehat{Y}_{1} \mathrm{o}$ valor da iésima área do cladódio após ajuste do modelo; $\bar{Y}$ é a média dos valores das áreas reais dos cladódios $\left(Y_{i}\right)$.

\section{RESULTADOS E DISCUSSÃo}

$\mathrm{Na}$ Tabela 3 verifica-se a correlação entre a variável dependente área real do claódido (ARC) e as variáveis explicativas: produto do comprimento pela largura (CL) e área da elipse. Nota-se que existe correlação positiva entre ARC e CL com coeficiente de correlação $r=0,90$, o mesmo é observado entre ARC e AE r=0,93.

TABELA 3. Correlação entre a área real de cladódio (ARC) e as variáveis explicativas: produto do comprimento e a largura (CL) e área da elipse $(A E)$

\begin{tabular}{cccc}
\hline & ARC & CL & AE \\
\hline ARC & 1,00 & 0,90 & 0,93 \\
CL & 0,90 & 1,00 & 0,99 \\
AE & 0,93 & 0,99 & 1,00 \\
\hline
\end{tabular}

$\mathrm{Na}$ avaliação da relação da área real de cladódio e o produto do comprimento e largura de cladódio do clone Orelha-de-Elefante-Mexicana, verifica-se que o modelo de regressão linear apresentou os melhores resultados dos critérios de adequação do modelo $\left(\mathrm{R}^{2}=96,66 \%\right.$, $\mathrm{SQR}=1,55$ e $\left.\mathrm{AIC}=-22,85\right)$ quando comparado aos modelos gamma e potência (Tabela 4).

TABELA 4. Estimativas dos parâmetros e critérios de adequação dos modelos levando em consideração a variável explicativa produto do comprimento e a largura $(\mathrm{CL})$ do cladódio do clone Orelha-de-Elefante-Mexicana

\begin{tabular}{lcccc}
\hline \multirow{2}{*}{ Modelos } & $\begin{array}{l}\text { Equação da Área } \\
\text { Real do Cladódio }\end{array}$ & \multicolumn{3}{c}{$\begin{array}{c}\text { Critérios de Adequação do } \\
\text { Modelo }\end{array}$} \\
\cline { 3 - 5 } & & $\mathbf{R}^{\mathbf{2}}$ & SQR & AIC \\
\hline Linear & $\mathrm{ARC}=2,165 \mathrm{CL}$ & 96,66 & 1,55 & $-22,85$ \\
Gamma & $\mathrm{ARC}=2,11 \mathrm{CL}$ & 80,00 & 1,55 & $-13,33$ \\
Potência & $\mathrm{ARC}=2,257 \mathrm{CL}^{1,106}$ & 80,67 & 1,53 & 5,53 \\
\hline
\end{tabular}

Resultados semelhantes utilizando medidas lineares foram verificados por Cardozo et al. (2011) analisando área foliar de Crotalaria juncea L., Lucena et al. (2011) avaliando área foliar de Malpighia emarginata, Leite et al. (2017) com Urochloa mosambicensis, Silva et al. (2017) em Manihot sp.

$\mathrm{Na}$ Figura 1, observam-se os valores da área real do cladódio e as estimativas dos modelos linear, gamma e potência em função do produto entre o comprimento e a largura do clone orelha de elefante Mexicana. 

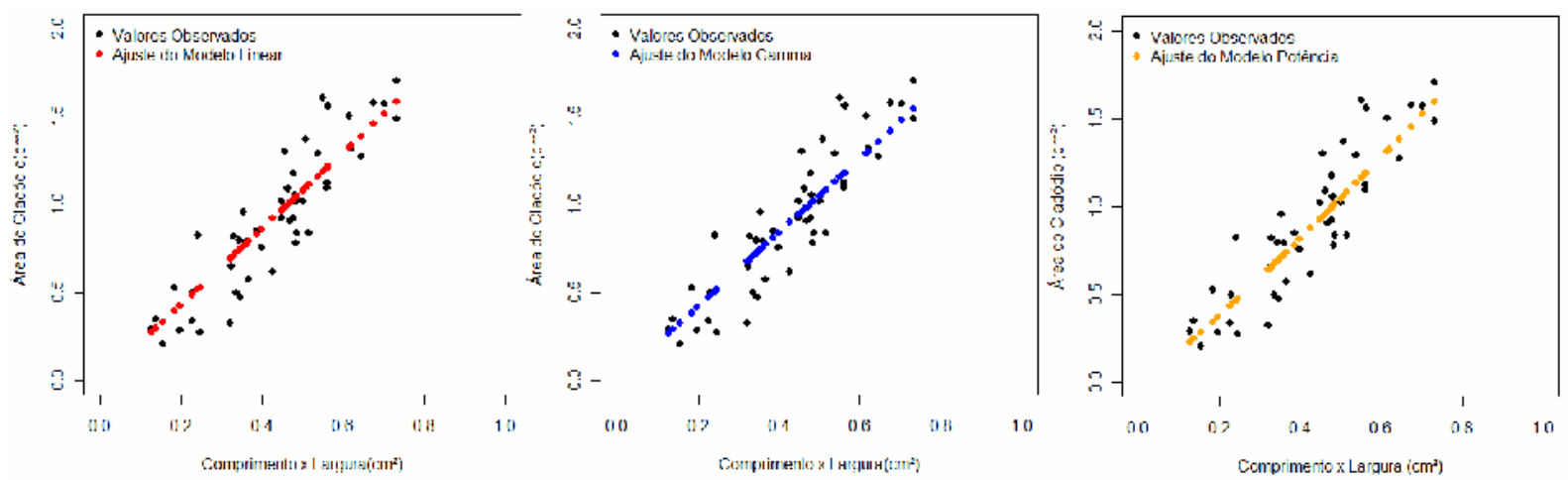

FIGURA 1. Estimativas da área de cladódio em função do produto do comprimento e largura do cladódio do clone Orelha-de-Elefante-Mexicana de diferentes modelos

$\mathrm{Na}$ avaliação da relação da área real de cladódio e a área da elipse do cladódio do clone Orelha-de-Elefante-Mexicana, verifica-se que o modelo de regressão linear apresentou os melhores resultados nos critérios de adequação do modelo $\left(R^{2}=96,77 \%\right.$, SQR $=1,38$ e $\left.A I C=-29,25\right)$ quando comparado aos modelos gamma e potência, Tabela 5 .

TABELA 5. Estimativas dos parâmetros e critérios de adequação dos modelos levando em consideração a variável explicativa como a área da elipse do (AE) do cladódio orelha de elefante mexicana

\begin{tabular}{llccc}
\hline \multirow{2}{*}{ Modelos } & $\begin{array}{l}\text { Equação da Área } \\
\text { Real do Cladódio }\end{array}$ & \multicolumn{3}{c}{$\begin{array}{c}\text { Critérios de Adequação do } \\
\text { Modelo }\end{array}$} \\
\cline { 3 - 5 } & & $\mathbf{R}^{\mathbf{2}}$ & SQR & AIC \\
\hline Linear & $\mathrm{ARC}=2,768 \mathrm{AE}$ & 96,77 & 1,38 & $-29,25$ \\
Gamma & $\mathrm{ARC}=2,712 \mathrm{AE}$ & 80,82 & 1,47 & $-14,87$ \\
Potência & $\mathrm{ARC}=2,933 \mathrm{AE} \mathrm{E}^{1,095}$ & 80,83 & 1,45 & 5,27 \\
\hline
\end{tabular}

$\mathrm{Na}$ Figura 2, observam-se os valores da área real de cladódio e as estimativas dos modelos linear, gamma e potência em função da área da elipse do cladódio do clone Orelha-de-Elefante-Mexicana.
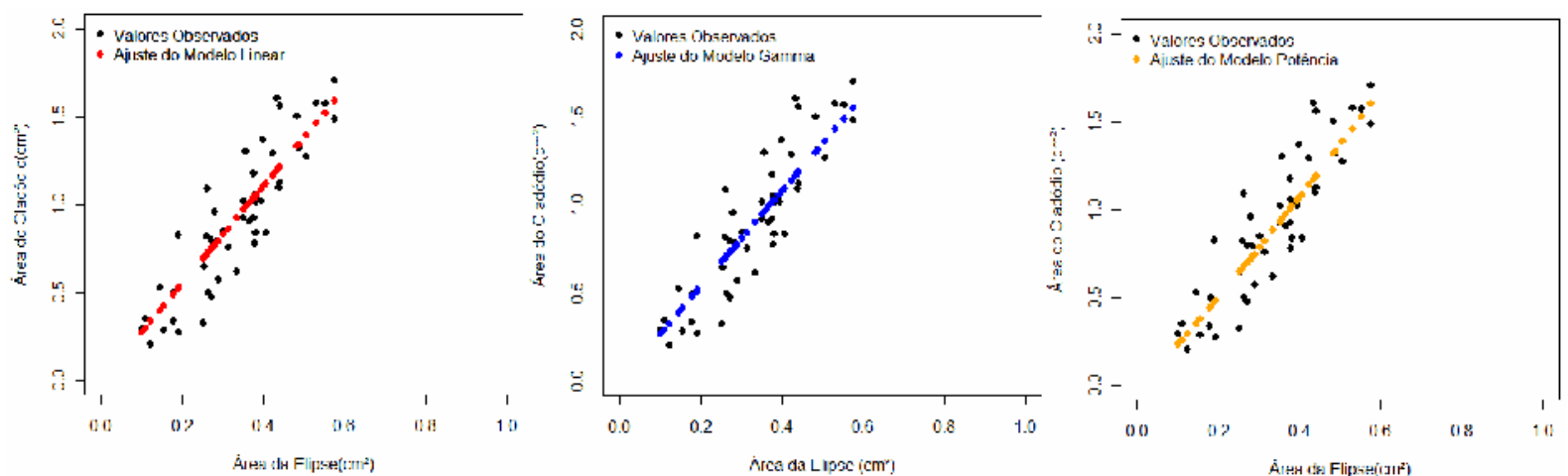

FIGURA 2. Estimativas da área do cladódio em função da área da elipse do cladódio orelha de elefante mexicana de diferentes modelos 
Levando em consideração os três critérios de adequação do modelo, observam-se nas Tabelas 4 e 5 que os modelos que melhor explicaram a área de cladódio do clone Orelha-de-Elefante-Mexicana foram os lineares. Os modelos lineares ajustados levando em consideração a variável explicativa $C L$ foi $A R C=2,165 \mathrm{CL}$ e considerando a variável explicativa $A E$ foi $A R C=2,768 \mathrm{AE}$.

Utilizando o modelo linear com variável explicativa $C L$, verifica-se que a cada aumento de um $\mathrm{cm}^{2}$ no produto do comprimento pela largura do cladódio tem-se em média um aumento de $2,165 \mathrm{~cm}^{2}$ na área real do cladódio, já utilizando o modelo linear com variável explicativa $A E$ a cada aumento de $u m \mathrm{~cm}^{2}$ na área da elipse temse em média um aumento de $2,768 \mathrm{~cm}^{2}$ na área real do cladódio.

Para um cladódio com $200 \mathrm{~cm}^{2}$ de $\mathrm{CL}$ e AE, respectivamente é esperado em média uma área real de cladódio de $433 \mathrm{~cm}^{2}$ e $553,6 \mathrm{~cm}^{2}$, respectivamente. Para um cladódio com $500 \mathrm{~cm}^{2}$ de $C L$ e $A E$, respectivamente é esperado em média uma área real de cladódio de 1082,5 $\mathrm{cm}^{2}$ e $1384 \mathrm{~cm}^{2}$, respectivamente, Figura 3 .

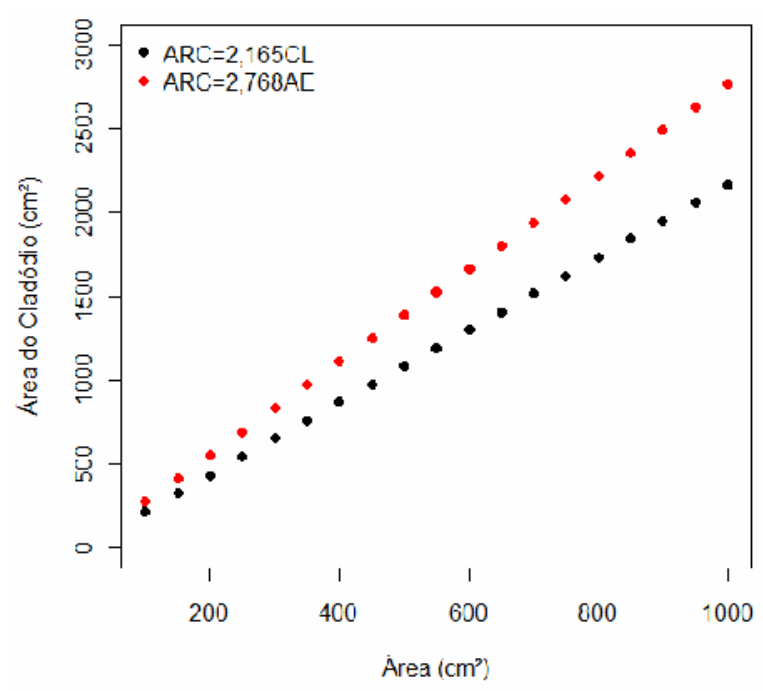

FIGURA 3. Estimativas da área do cladódio do clone Orelha de Elefante Mexicana em função da área do comprimento e largura e da elipse

\section{CONCLUSÃO}

A modelagem matemática que melhor se ajusta para explicar a área de cladódio Orelha-de-Elefante-Mexicana é o linear com variável explicativa a área da elipse.

\section{REFERÊNCIAS}

ACHTEN, W.M.J.; MAES, W.H.; REUBENS, B.; MATHIJS, E.; SINGH, V.P.; et al. Biomass production and allocation in Jatropha curcas $L$. seedlings under different levels of drought stress. Biomass and Bioenergy, v. 34, n. 5, p. 667-676, 2010. Disponível <https://www.sciencedirect.com/science/article/pii/S0961953410000115> em: 10.1016/j.biombioe.2010.01.010 
AKAIKE, $\mathrm{H}$. A new look at the statistical model identication. IEEE Transactions on automatic Control, v. 19, n. 6, p.716-723, 1974. Disponível em: <http://ieeexplore.ieee.org/document/1100705> doi:10.1109/TAC.1974.1100705

ANDRADE, S.F.J.D.; BATISTA, A.M.V.; CARVALHO, F.F.R.D.; LUCENA, R.B.D.; ANDRADE, R.D.P.X.D.; et al. Fresh or dehydrated spineless cactus in diets for lambs. Acta Scientiarum. Animal Sciences, v.38, n.2, p.155-161, 2016. Disponível em:< http://www.scielo.br/pdf/asas/v38n2/1807-8672-asas-38-02-00155.pdf> doi: 10.4025/actascianimsci.v38i2.29329

ANTUNES, W.C.; POMPELLI, M.F.; CARRETERO, D.M.; DAMATTA, F.M. Allometric models for nondestructive leaf area estimation in coffee (Coffea arabica and Coffea canephora). Annals of Applied Biology, v. 153, p. 33-40, 2008. Disponível em:< https://onlinelibrary.wiley.com/doi/abs/10.1111/j.1744-7348.2008.00235.x> doi: 10.1111/j.1744-7348.2008.00235.x

AQUINO, L.A.; SANTOS JUNIOR, V.C.; GUERRA, J.V.S.; COSTA, M.M. Estimativa da área foliar do girassol por método não destrutivo. Bragantia, v. 70, n. 4, p. 832836, 2011. Disponível em: <http://www.scielo.br/scielo.php?pid=S000687052011000400015\&script=sci_abstract\&tlng=pt> doi: 10.1590/S000687052011000400015

CARDOZO, N.P.; PARREIRA, M.C.; AMARAL, C.L.; ALVES, P.L.C.A.; BIANCO, S. Estimativa da área foliar de Crotalaria juncea $L$. a partir de dimensões lineares do limbo foliar. Bioscience Journal, v. 27, n. 6, p. 902-907, 2011. Disponível em:< http://www.seer.ufu.br/index.php/biosciencejournal/article/view/12123/8115>

CARGNELUTTI FILHO, A.; TOEBE, M.; BURIN, C.; FICK, A.L.; NEU, I.M.M.; et al. Estimação de área foliar de mucuna cinza por meio de método não-destrutivo. Ciência Rural, v. 42, n. 2, p. 238-242, 2012. Disponível em:< http://www.scielo.br/scielo.php?pid=S0103-

84782012000200009\&script=sci_abstract\&tIng=pt> doi: 10.1590/S010384782012000200009

DUBEUX JR, J.C.B.; FILHO, J.T.A.; SANTOS, M.V.F.; LIRA, M.A.; SANTOS, D.C.; et al. Adubação mineral no crescimento e composição mineral da palma forrageira clone ipa-201s. Revista Brasileira de Ciências Agrárias, v. 5, n. 1, p.129-135, 2010. Disponível em:< http:/www.agraria.pro.br/ojs2.4.6/index.php?journal=agraria\&page=article \&op=view\&path\%5B\%5D=agraria_v5i1 a591\&path\%5B\%5D=37> doi: 10.5039/agraria.v5i1a591

EMBRAPA - Embrapa Solos. Manual de métodos de análise de solo. Brasília: Embrapa Informação Tecnológica; Brasília, DF: Embrapa Solos, 2017. 575p. Disponível em:<https://www.embrapa.br/solos/busca-de-publicacoes//publicacao/1085209/manual-de-metodos-de-analise-de-solo>

FLUMIGNAN, D.L.; ADAMI, M., FARIA, R.T. Área foliar de folhas integras e danificadas de cafeeiro determinada por dimensões foliares e imagem digital. Coffee Science, v. 3, n. 1, p. 1-6, 2008. Disponível em:< 
https://www.researchgate.net/profile/Marcos_Adami/publication/43652817_Area_folia r_de_folhas_A-

ntegras_e_danificadas_de_cafeeiro_determinada_por_dimensAes_foliares_e_image m_digital/links/55a547b308aef604aa043268/Area-foliar-de-folhas-A-ntegras-e-

danificadas-de-cafeeiro-determinada-por-dimensAes-foliares-e-imagem-digital.pdf> doi: 10.25186/cs.v3i1.67

FRANCISCO, J.P.; DIOTTO, A.V.; FOLEGATTI, M.V.; SILVA, L.D.B.; PIEDADE, S.M.S. Estimativa da área foliar do abacaxizeiro cv. Vitória por meio de relações alométricas. Revista Brasileira de Fruticultura, v. 36, n. 2, p. 285- 293, 2014. Disponível em:< http://www.scielo.br/pdf/rbf/v36n2/v36n2a03.pdf> doi: 10.1590/01002945-216/13

LEITE, M.L.M.V.; LUCENA, L.R.R.; SÁ JUNIOR, E.H.; CRUZ, M.G. Estimativa da área foliar em Urochloa mosambicensis por dimensões lineares. Revista Agropecuária Técnica, v. 38, n. 1, p. 9-16, 2017. Disponível em:< http://www.periodicos.ufpb.br/ojs/index.php/at/article/view/32041/17513> doi: 10.25066/agrotec.v38i1.32041

LIMA, R.T.; SOUZA, P.J.O.P.; RODRIGUES, J.C.; LIMA, M.J.A. Modelos para estimativa da área foliar da mangueira utilizando medidas lineares. Revista Brasileira de Fruticultura, v. 34, n. 4, p. 974-980, 2012. Disponível em:< http://www.scielo.br/scielo.php?pid=S0100-

29452012000400003\&script=sci_abstract\&tIng=pt> doi: 10.1590/S010029452012000400003

LUCENA, R.R.M.; BATISTA, T.M.V.; DOMBROSKI, J.L.D.; LOPES, W.A.R.; RODRIGUES, G.S.O. Medição de área foliar de aceroleira. Revista Caatinga, v. 24, n. 2, p. 40-45, 2011. Disponível em:< https://periodicos.ufersa.edu.br/index.php/caatinga/article/view/1728/4710>

MORGADO, M.A.D.; BRUCKNER, C.H.; ROSADO, L.D.S.; ASSUNÇÃO, W.; SANTOS, C.E.M. Estimação da área foliar por método não destrutivo, utilizando medidas lineares das folhas de espécies de Passiflora. Revista Ceres, v. 60, n. 5, p. 662-667, 2013. Disponível em:< http://www.scielo.br/scielo.php?pid=S0034737X2013000500009\&script=sci_abstract\&tIng=pt> doi: 10.1590/S0034$737 \times 2013000500009$

PINHEIRO, K.M; SILVA, T.G.F.; CARVALHO, H.F.S.; SANTOS, J.E.O.; MORAIS, J.E.F.; et al. Correlações do índice de área do cladódio com características morfogênicas e produtivas da palma forrageira. Pesquisa Agropecuária Brasileira, v.49, n.12, p.939-947, 2014. Disponível em: <http://www.scielo.br/pdf/pab/v49n12/0100-204X-pab-49-12-00939.pdf> doi: 10.1590/S0100-204X201400120000

RAMOS, J.P.F.; LEITE, M.L.D.M.V.; JUNIOR, S.O; NASCIMENTO, J.P.; SANTOS, E.M. Crescimento vegetativo de opuntia ficus-indica em diferentes espaçamentos de 
plantio. Revista Caatinga, v.24, n.3, p.41-48, 2011. Disponível em:< https://periodicos.ufersa.edu.br/index.php/caatinga/article/view/1602/4743>

SBRISSIA, A.F.; SILVA, S.C. Comparação de três métodos para estimativa do índice de área foliar em pastos de capim-marandu sob lotação contínua. Revista Brasileira de Zootecnia, v. 37, n. 2, 212-220, 2008. Disponível em:< http://www.scielo.br/scielo.php?script=sci_arttext\&pid=S1516-35982008000200006> doi: 10.1590/S1516-35982008000200006

SCHMILDT, E.R.; AMARAL, J.A.T.; SCHMILDT, O.; SANTOS, J.S. Análise comparativa de equações para estimativa da área foliar em cafeeiros. Coffee Science, v. 9, n. 2, p. 155-167, 2014. Disponível em:< http://www.coffeescience.ufla.br/index.php/Coffeescience/article/view/573> doi: $10.25186 /$ cs.v9i2.573

SILVA, G.L.S.; CARNEIRO, M.S.S.; EDVAN, R.L.; ANDRADE, A.P.; MEDEIROS, G.R.; et al. Determining a model to estimate leaf area in Pornunça (Manihot $\mathrm{sp}$. ) using morphometric measures. Acta Scientiarum. Animal Science, v. 39, n. 4, p. 351-256, $2017 . \quad$ Disponível em:< http://www.scielo.br/scielo.php?script=sci_arttext\&pid=S1807-86722017000400351 > doi: 10.4025/actascianimsci.v39i4.36447

SILVA, L.M.; FAGUNDES, J.L.; VIEGAS, P.A.A.; MUNIZ, E.N.; RANGEL, J.H.A.; et al. Produtividade da palma forrageira cultivada em diferentes densidades de plantio. Revista Ciência Rural, v.44, n.11, p.2064-2071, 2014. Disponível em: <http://www.scielo.br/pdf/cr/v44n11/0103-8478-cr-44-11-02064.pdf> doi: 10.1590/0103-8478cr20131305

SILVA, N.G.M.; LIRA, M.A.; SANTOS, M.V.F.; DUBEUX JR, J.C.B.; MELLO, A.C.L.; et al.. Relação entre características morfológicas e produtivas de clones de palma forrageira. Revista Brasileira de Zootecnia, v.39, p.2389 2397, 2010. Disponível em:< http://www.scielo.br/pdf/rbz/v39n11/v39n11a11.pdf> doi: 10.1590/S1516 35982010001100011.

TOEBE, M.; CARGNELUTTI FILHO, A.; LOOSE, L.H.; HELDWEIN, A.B.; ZANON, A.J. Área foliar de feijão-vagem (Phaseolus vulgaris L.) em função de dimensões foliares. Semina: Ciências Agrárias, v. 33, n. 1, p. 2491-2500, 2012. Disponível em:< http://www.uel.br/revistas/uel/index.php/semagrarias/article/view/8008 > doi: 10.5433/1679-0359.2012v33Supl1p2491 